\title{
From Evolutionary Medicine to Precision Medicine in the Hypertension Treatment in Africa
}

\author{
Ângela Inácio ${ }^{1 *}$, Laura Aguiar ${ }^{2}$ and Manuel Bicho ${ }^{3}$ \\ ${ }^{1}$ Ecogenetics and Human Health, Instituto de Saúde Ambiental, Lisboa, Portugal \\ ${ }^{2}$ Laboratório de Genética, Faculdade de Medicina da Universidade de Lisboa, Portugal \\ ${ }^{3}$ Instituto de Investigação Bento da Rocha Cabral, Lisboa, Portugal
}

*Corresponding author: Ângela Inácio, Ecogenetics and Human Health, Instituto de Saúde Ambiental, Lisboa, Portugal; E-mail: minacio@medicina.ulisboa.pt

Received: September 27, 2021; Accepted: October 04, 2021; Published: October 08, 2021

\begin{abstract}
In ancient humans from Africa populations the hot, dry, and salt-scarce climate have almost certainly selected an efficient capacity to perspire and the development of mechanisms for the conservation of sodium in the kidneys. The more recent development of African cities following western lifestyles is revealing these selected compensatory mechanisms by means of hypertension. Africa expands from North to South $\left(70^{\circ}\right.$ latitude), presenting an enormous diversity of climates and natural environments associated with different selective pressures. In order to improve hypertension treatment in Africa it is needed to obtain new genomic data from the different African ethnic groups, as this is the only way we can put into practice precision medicine based on evolutionary medicine.

Traditional medicine restricts itself to the study of causality inserted in a short period of time, most often dealing with the present symptomatology (acute symptoms), or sometimes also considering the natural history of the disease and the associated chronic symptomatology. Hereditary and genetically predisposed diseases further extend this time window, including the study of several generations of the patient's family. However, when the approach to medicine is evolutionary, the time factor changes scale, as the search for causality invokes adaptive processes inherent to evolutionary mechanisms, such as natural selection.
\end{abstract}

After the emergence of the genus Homo in Africa, hominids occupied a wide variety of environments. It is now believed that Homo sapiens has originated in Africa about 500,000 to 300,000 years ago, according to a "Pan-African" model, in which gene exchange was possible through sporadic crossbreeding between geographically distinct populations of Homo sapiens or even other hominids [1-4]. Regions located near the equator have higher diversity of pathogens, and consequently have been the scene for outbreaks of meningitis, Ebola and malaria [5-7]. Some genetic variants that confer resistance to malaria are classic examples of the selection of alleles that, in homozygosity, predispose individuals to severe genetic diseases, such as sickle cell disease. Here, the existence of a large availability of food, delayed industrialization in Africa, once compared to the other cities of western culture. Africa's later urban development has had a profound impact on health, especially in countries with the highest rates of development. For example, regarding high blood pressure, it occurs more frequently, earlier and more severely in African individuals or individuals of African descent [8]. Hypertension is a relevant public health problem, being a risk factor for cardiovascular disease and kidney failure. Hypertension affects about $25 \%$ of the adult population in the world and It is known to have a genetic $[9,10]$.

From an evolutionary perspective, there is evidence that susceptibility to hypertension may be ancestral, and that part of the differences presented are explained by exposure to different selective pressures. The desire for salt and water and vascular reactivity, key components of susceptibility to hypertension, must have been adaptively acquired in the ancestral African environment characterized by a hot, dry and salt-scarce climate [11]. Heat dissipation is essential in hot environments and is achieved most efficiently through its loss through evaporation, consequently humans have developed an enormous capacity to perspire. However, excessive transpiration can lead to significant losses of salt and water, which together with the low availability of salt in tropical climates, results on one hand in an increased demand for salt and on the other in the development of mechanisms for the conservation of sodium in the kidneys. In fact, it turns out that humans and non-human primates from tropical regions have a greater desire for salt and water [12-15]. Another consequence of excessive sweating is the loss of blood volume, with a subsequent increase in arterial tone and cardiac contraction in order to guarantee blood pressure and effective perfusion in the organs [16]. Thus, the genetic variation associated with these compensatory mechanisms related to the increase in arterial and cardiac contractility must certainly have constituted an advantage in the environmental context of human evolution in its most primordial phase.

Originating in Africa, our species ended up conquering new territories, expanding to other regions of the globe, at different latitudes, facing different environments. Then there was a need to adapt to new thermodynamic control mechanisms, in which the objective progressively stopped being the dissipation of heat, but rather its conservation. On the other hand, selection by demand for salt and 
water and cardiovascular reactivity decreased $[17,18]$. Thus, the greater susceptibility to hypertension in African populations, compared to the non-African ones, results from physiological adaptations to different environments that were progressively imprinted in the genomes for about 30,000 years [19]. The most recent development of African metropolises, associated with a more stressful lifestyle, an increase in the consumption of fast-food products, with high levels of salt and promoters of overweight/obesity, highlighted the health problems that these populations face in the area of hypertension and cardiovascular diseases, revealing the synergistic effects of exposure to new lifestyles with the evolutionary processes encrypted in their genomes [19].

Currently, several genes with polymorphic variation that code for proteins involved in compensatory mechanisms of volume change and vascular reactivity, secondary to salt loss, have been identified [19]. For example, the haptoglobin gene, which has polymorphic variation only in humans, codes for an acute-phase protein that has been associated with high levels of sodium-sensitive blood pressure for more than 30 years. Population studies have shown similar allelic frequencies between two countries located at similar latitudes - Honduras (Central America) and Mozambique (Africa) [20]. In this case, it is interest to observe that the Native American population (Honduras), despite being more recent and coming from cold-adapted populations from North Asia, is genetically similar to the more ancestral one (Mozambique), reflecting a more recent adaptation that occurred in less than 20,000 years, demonstrating the strength of selection by latitude. Another gene traditionally associated with hypertension, the GNB3, has been shown to contribute to the disease in a latitude-dependent manner [19]. Evidence of selection by latitude was also found in mitochondrial genes linked to oxidative phosphorylation, and therefore also in the production of heat by cells, essential for adaptation to external temperatures [21].

The genetic variability between populations fixed by selective pressures is particularly relevant when it is intended to implement precision medicine, in which a more personalized treatment, which considers the individual's genetic profile, allows for a more targeted therapeutic intervention. This approach is very relevant when dealing with multifactorial diseases (such as hypertension), in which several genes in partnership with the environment shape the individual's phenotype. Precision medicine tends to use information obtained through new mass sequencing technologies. However, the few technological resources that exist in Africa, limit the collection of these data [22]. Only a small number of health and/or research institutions contribute with data, but often targeting only already known genes, thus limiting the discovery of variants in new genes [22]. In fact, an analysis of several genome-wide studies revealed that Africa is underrepresented, despite having a large number of associations between genetic variants and various diseases [23]. The relevance of these studies grows if we consider the great genetic diversity that exists within this continent. Africa expands from North to South $\left(70^{\circ}\right.$ latitude), presenting an enormous diversity of climates and natural environments associated with different selective pressures. The African diaspora that happened about 70,000 years ago, occurred via a population bottleneck effect, as it is estimated that only about
1,000 individuals of East African descent have achieved this effect [24,25]. In this way, the African populations, more ancestral, end up presenting a greater genetic diversity compared to others. Then, there is an urgent need to obtain genomic data from the different African ethnic groups, as this is the only way we can put into practice precision medicine based on evolutionary medicine.

\section{References}

1. Hublin J-J, Ben-Ncer A, Bailey SE, Freidline SE, Neubauer S, et al. (2017) New fossils from Jebel Irhoud, Morocco and the pan-African origin of Homo sapiens. Nature 546: 289-292.

2. Scerri EML, Thomas MG, Manica A, Gunz P, Stock JT, et al. (2018) Did Our Species Evolve in Subdivided Populations across Africa, and Why Does It Matter? Trends in Ecology \& Evolution 33: 582-594. [crossref]

3. Schlebusch CM, Malmström H, Günther T, Sjödin P, Coutinho A, et al. (2017) Southern African ancient genomes estimate modern human divergence to 350,000 to 260,000 years ago. Science 358: 652-655. [crossref]

4. Stringer C (2016) The origin and evolution of homo sapiens. Philosophical Transactions of the Royal Society B: Biological Sciences 371.

5. Alexander KA, Sanderson CE, Marathe M, Lewis BL, Rivers, CM, et al. (2015) What factors might have led to the emergence of Ebola in West Africa? PLoS Neglected Tropical Diseases 9: e0003652. [crossref]

6. Cairns ME, Walker PGT, Okell LC, Griffin JT, Garske T, et al. (2015) Seasonality in malaria transmission: implications for case-management with long-acting artemisinin combination therapy in sub-Saharan Africa. Malaria Journal 14: 321

7. Zhao S, Lin Q, He D, Stone L (2018) Meningitis epidemics shift in sub-Saharan belt. International Journal of Infectious Diseases: IJID : Official Publication of the International Society for Infectious Diseases 68: 79-82.

8. Burt VL, Whelton P, Roccella EJ, Brown C, Cutler JA, et al. (1995) Prevalence of hypertension in the US adult population: results from the Third National Health and Nutrition Examination Survey, 1988-1991. Hypertension 25: 305-313. [crossref]

9. Kearney PM, Whelton M, Reynolds K, Muntner P, Whelton PK, et al. (2005) Global burden of hypertension: analysis of worldwide data. Lancet 365: 217-223. [crossref]

10. Luft FC (2021) [Molecular genetics of human hypertension]. Der Internist 62: 223235. [crossref]

11. Bicho M (2018) Genetic predisposition for essential hypertension, based on studies of genetic polymorphisms in modern global human populations: The perspective of evolutionary biology. Revista Portuguesa de Cardiologia 37: 509-510.

12. Baker EH, Ireson NJ, Carney C, Markandu ND, MacGregor GA (2001) Transepithelial sodium absorption is increased in people of African origin. Hypertension 38: 76-80. [crossref]

13. Brier ME, Luft FC (1994) Sodium kinetics in white and black normotensive subjects: possible relevance to salt-sensitive hypertension. The American Journal of the Medical Sciences 307: S38-42. [crossref]

14. Moskowitz DW (1996) Hypertension, thermotolerance, and the "African gene": an hypothesis. Clinical and Experimental Hypertension 18: 1-19.

15. Vollmer WM, Sacks FM, Ard J, Appel LJ, Bray GA, et al. (2001) Effects of diet and sodium intake on blood pressure: subgroup analysis of the DASH-sodium trial. Annals of Internal Medicine 135: 1019-1028. [crossref]

16. Newman RW (1970) Why man is such a sweaty and thirsty naked animal: A speculative review. Human Biology 12-27. [crossref]

17. Cardillo C, Kilcoyne CM, Cannon RO, Panza JA (1999) Attenuation of cyclic nucleotide-mediated smooth muscle relaxation in blacks as a cause of racial differences in vasodilator function. Circulation 99: 90-95. [crossref]

18. Stein CM, Lang CC, Singh I, He HB, Wood AJ (2000) Increased vascular adrenergic vasoconstriction and decreased vasodilation in blacks Additive mechanisms leading to enhanced vascular reactivity. Hypertension 36: 945-951. [crossref]

19. Young JH, Chang Y-PC, Kim JD-O, Chretien J-P, Klag MJ, Levine MA, et al. (2005) Differential susceptibility to hypertension is due to selection during the out-of-Africa expansion. PLoS Genetics 1: e82. [crossref] 
Ângela Inácio (2021) From Evolutionary Medicine to Precision Medicine in the Hypertension Treatment in Africa

20. Silva AP, Damasceno A, Ricchiuti V, Polónia J, Fisher N, Bicho (2012) Revista Portuguesa de Hipertensão e Risco cardiovascular 34.

21. Starikovskaya EB, Sukernik RI, Derbeneva OA, Volodko NV, Ruiz-Pesini E, et al. (2005) Mitochondrial DNA diversity in indigenous populations of the southern extent of Siberia, and the origins of Native American haplogroups. Annals of Human Genetics 69: 67-89. [crossref]

22. Pereira L, Mutesa L, Tindana P, Ramsay M (2021) African genetic diversity and adaptation inform a precision medicine agenda. Nature Reviews Genetics 22: 284306. [crossref]
23. Gurdasani D, Barroso I, Zeggini E, Sandhu MS (2019) Genomics of disease risk in globally diverse populations. Nature Reviews Genetics 20: 520-535.

24. Gravel S, Henn BM, Gutenkunst RN, Indap AR, Marth GT, et al. (2011) Demographic history and rare allele sharing among human populations. Proceedings of the National Academy of Sciences of the United States of America 108: 11983-11988.

25. Macaulay V, Hill C, Achilli A, Rengo C, Clarke D, et al. (2005) Single, rapid coastal settlement of Asia revealed by analysis of complete mitochondrial genomes. Science 308: 1034-1036. [crossref]

\section{Citation:}

Inácio A, Aguiar L, Bicho M (2021) From Evolutionary Medicine to Precision Medicine in the Hypertension Treatment in Africa. Internal Med Res Open J Volume 6(5): $1-3$. 